06,13

\title{
Диэлектрические и сегнетоэлектрические свойства тонких гетероэпитаксиальных пленок SBN-50
}

\author{
(C) А.В. Павленко ${ }^{1,3}$, Д.А. Киселев ${ }^{2}$, Я.Ю. Матяш ${ }^{1}$ \\ ${ }^{1}$ Федеральный исследовательский центр Южный научный центр РАН, \\ Ростов-на-Дону, Россия \\ ${ }^{2}$ Национальный исследовательский технологический университет „МИСиС“, \\ Москва, Россия \\ ${ }^{3}$ Научно-исследовательский институт фризики Южного федерального университета, \\ Ростов-на-Дону, Россия \\ E-mail: Antvpr@mail.ru
}

Поступила в Редакцию 22 февраля 2021 г.

В окончательной редакции 22 февраля 2021 г.

Принята к публикации 24 февраля 2021 г.

\begin{abstract}
С использованием методов диэлектрической спектроскопии и сканирующей зондовой микроскопии (в режимах силовой микроскопии пьезоотклика и Кельвин моды) проведены исследования фазовых превращений и сегнетоэлектрических характеристик тонких пленок ниобата бария-стронция SBN-50, выращенных методом ВЧ-катодного распыления в атмосфере кислорода. Показано, что пленки характеризуются низкой шероховатостью поверхности, средним размером сегнетоэлектрических доменов $\sim 100 \mathrm{~nm}$ и самопроизвольной поляризацией, направленной от подложки к поверхности пленки. Установлены различия в величине сигнала поверхностного потенциала и его релаксация для областей, заполяризованных внешним полем различной полярности $(+10$ и $-10 \mathrm{~V})$. Характер изменения диэлектрических параметров в интервале температур $T=275-500 \mathrm{~K}$ свидетельствует о принадлежности материала к сегнетоэлектрикам-релаксорам. Обсуждаются причины установленных закономерностей.
\end{abstract}

Ключевые слова: тонкие пленки, ниобат бария-стронция, сканирующая зондовая микроскопия.

DOI: 10.21883/FTT.2021.06.50939.035

\section{1. Введение}

Тонкие пленки (ТП) бессвинцовых сегнетоэлектриков привлекают к себе большое внимание, что обусловлено как перспективами их применения в датчиках, сенсорах, и устройствах МЭМС [1], так и исследованиями размерных эффектов в наноструктурах [2]. Твердые растворы (TP) $\mathrm{Sr}_{x} \mathrm{Ba}_{1-x} \mathrm{Nb}_{2} \mathrm{O}_{6}$ (SBN-x, $x-$ стехиометрический коэффициент) являются типичными представителями данной группы объектов благодаря высоким значениям диэлектрической проницаемости, электрооптическим и пироэлектрическим эффектам. Температура фазового перехода $(Ф П)$ из тетрагональной сегнетоэлектрической $(\mathrm{CЭ})$ фазы $(P 4 \mathrm{bm})$, сохраняющейся, по всей видимости, и в наноразмерных пленках, в параэлектрическую (ПЭ) (P4b2) увеличивается по мере снижения содержания $\mathrm{Sr}^{2+}$ [3]. Фазовый переход сопровождается аномальным поведением в диэлектрических характеристиках и оптических свойствах, динамике решетки и структурных характеристиках, что подробно изучено в крупнокристаллических образцах $\mathrm{SBN}-x$, а в ТП эти исследования проводились фрагментарно и в ряде случаев носят противоречивый характер. Вероятностное заселение каналов $A 1$ и $A 2$ в структуре типа тетрагональных вольфрамовых бронз катионами $\mathrm{Sr}^{2+}$ и $\mathrm{Ba}^{2+}$ приводит к проявлению в данных материалах релаксорных свойств, что находит отражение и в их доменной структуре - в равновесной доменной структуре объемные сегнетоэлектрические домены („игль“ длиной до $500 \mu \mathrm{m}$ и диаметром до $10 \mu \mathrm{m}$ ) сосуществуют с приповерхностными наноразмерными доменами (их параметры сильно зависят от состава), а при приложении внешнего поля происходит монодоменизация [4]. В тонких пленках $\mathrm{SBN}-x$ доменная структура практически не изучалась, хотя к настоящему времени они успешно получены различными методами (золь-гель, металлоорганическим осаждением, магнетронным осаждением и др.) на подложках $\mathrm{Si}, \mathrm{SrTiO}_{3}$ и $\mathrm{MgO}$. В частности, в [5] представлены результаты об эффективном использовании пленок ниобата бариястронция при изготовлении электрооптического модулятора с высокой добротностью, в [6] - при изготовлении структур металл-сегнетоэлектрик-полупроводник, перспективных для применения в МЭМС и разработке элементов энергонезависимой памяти. В [7] показаны возможности согласования элементарных ячеек SBN- $x$ и $\mathrm{MgO}(001)$ при гетероэпитаксиальном сопряжении. В настоящей работе представлены результаты исследования диэлектрических, сегнетоэлектрических и пьезоэлектрических характеристик выращенных методом ВЧ-катодного распыления ТП $\mathrm{Sr}_{0.50} \mathrm{Ba}_{0.50} \mathrm{Nb}_{2} \mathrm{O}_{6}$ (SBN-50) на подложках $\mathrm{SrRuO}_{3}(001) / \mathrm{MgO}(001)$. 

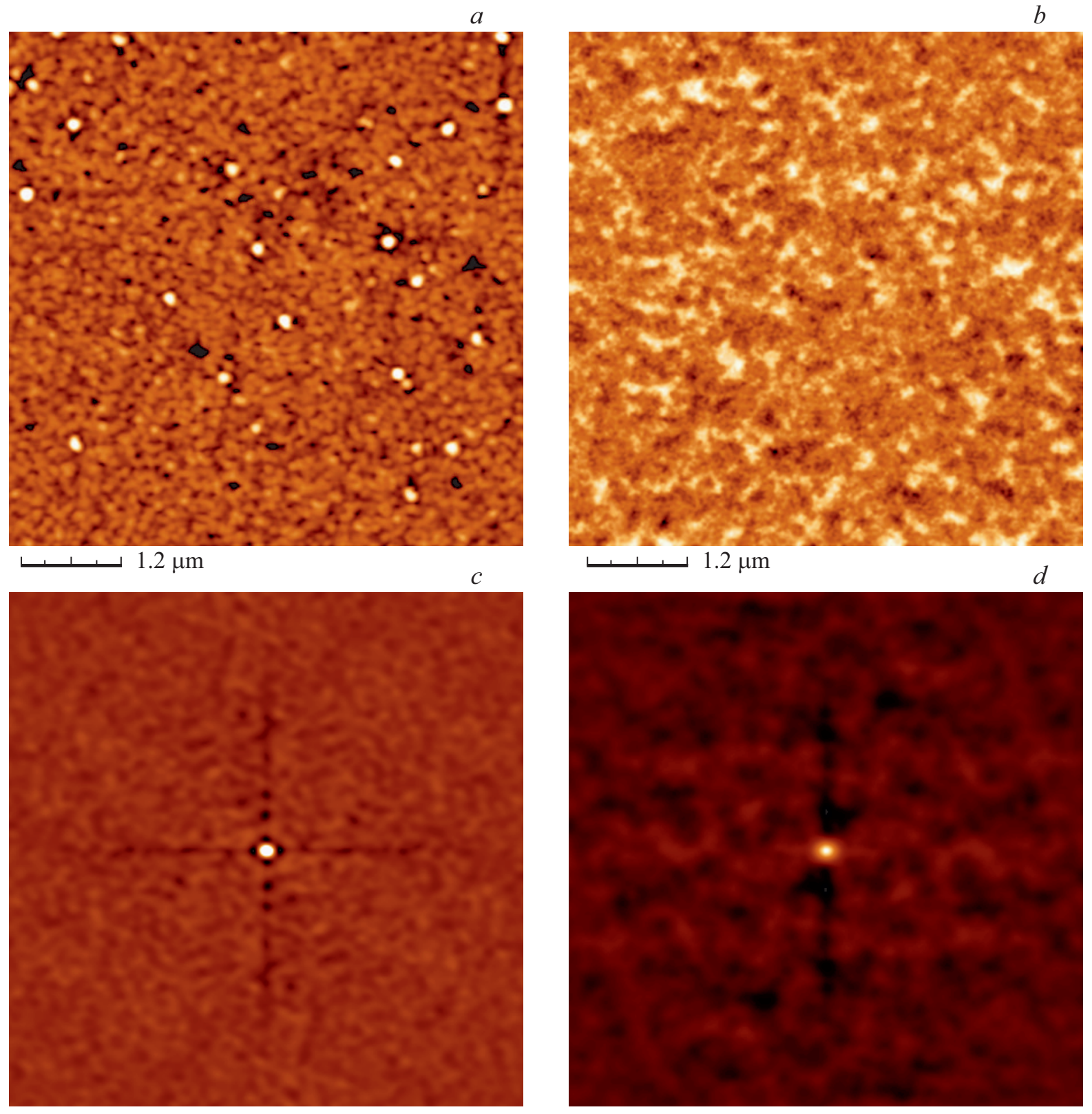

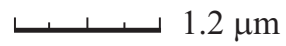

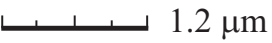

Рис. 1. Изображение поверхности пленки SBN-50 $(a)$ и сигнал пьезоотклика $(b, c$ и $d)-2 \mathrm{D}$-представление автокорреляционной функции топографии и доменной структуры соответственно.

\section{2. Объекты. Методы получения и исследования}

Газоразрядное RF-напыление гетероэпитаксиальных пленок SBN-50 осуществлялось на установке „Плазма 50 СЭ“. В качестве подложки использовался монокристаллический $\mathrm{MgO}(001)$ толщиной $0.5 \mathrm{~mm}$ (МТI Corporation, USA), на поверхность которой предварительно был осажден гетероэпитаксиально слой $\mathrm{SrRuO}_{3}$ (001). Начальная температура подложки - $400^{\circ} \mathrm{C}$, давление чистого кислорода в камере - 0.5 Torr, ВЧ-мощность - $110 \mathrm{~W}$, расстояние мишень подложка -
$12 \mathrm{~mm}$. Толщина пленок рассчитывалась по времени напыления (скорость роста $\sim 5.5-6 \mathrm{~nm} / \mathrm{min}$ ). Учитывая $[7,8]$, в этих рамках используемого метода состав пленок сохраняется, а легирование пленки конструкционными элементами не происходит.

Для проведения диэлектрических измерений в направлении, перпендикулярном плоскости пленки, на свободную поверхность пленки через маску с отверстиями диаметром $\sim 200 \mu \mathrm{m}$ осаждались электроды методом термического испарения Al в вакууме. В качестве нижнего электрода выступал слой $\mathrm{SrRuO}_{3}$. Относительная диэлектрическая проницаемость $\varepsilon / \varepsilon_{0}$ определялась из 
соотношения $C=\varepsilon \varepsilon_{0} S / h$, где $C-$ емкость структуры, $h$ - толщина слоя сегнетоэлектрика, $S$ - площадь электрода, $\varepsilon_{0}=8.854 \cdot 10^{-12} \mathrm{~F} / \mathrm{m}$ - электрическая постоянная. Площадь электрода измерялась на 3D-микроскопе KeyenceVK-9700 (Объединенный центр научнотехнологического оборудования ЮНЦ РАН). Зависимости от температуры $\varepsilon / \varepsilon_{0}$ и тангенса угла диэлектрических потерь $\operatorname{tg} \delta$ в диапазоне частот $f=200-10^{6} \mathrm{~Hz}$ с амплитудой $0.02 \mathrm{~V}$ получали с помощью измерительного стенда на базе LCR-метра Agilent 4980A. Измерения вольт-кулонных характеристик $P(U)$ при комнатной температуре, которые позволили оценить величину остаточной поляризации $\left(P_{R}\right)$ величину коэрцитивного поля $\left(E_{c}\right)$, СЭ-усталость, осуществлялись на анализаторе TFAnalyzer2000.

Топография, доменная структура, процессы локального переключения и релаксация сигнала заполяризованных областей пленок получены на сканирующем зондовом микроскопе NtegraPrima (NT-MDTSI, Россия) в режимах силовой микроскопии пьезоотклика (CMП) и Кельвин моды (КМ) с использованием кантилевера марки Asyelec-02 (AsylumResearch, США). Обработка и анализ изображений осушествлялась в программах Gwyddion и WSxM [9].

\section{3. Экспериментальные результаты и обсуждение}

На рис. 1 представлены изображения топографии поверхности гетероструктуры $\mathrm{Sr}_{0.5} \mathrm{Ba}_{0.5} \mathrm{Nb}_{2} \mathrm{O}_{6} /$ $\mathrm{SrRuO}_{3}(001) / \mathrm{MgO}(001)$. Поверхность пленки является однородной, включений примесных фаз, пор и каверн не наблюдалось, а шероховатость достаточно низкая (среднеквадратичная шероховатость поверхности Rms пленки толщиной $\sim 200 \mathrm{~nm}$ составила менее $5 \mathrm{~nm}$ ). Для количественной оценки латерального размера кристаллитов и сегнетоэлектрических доменов нами использовался метод автокорреляционной функции, имеющей следующий вид [10]:

$$
C\left(r_{1}, r_{2}\right)=\sum_{x, y} f(x, y) f\left(x+r_{1}, y+r_{2}\right),
$$

где $f(x, y)$ - матрица изображения. Уравнение (1) показывает исходное изображение и смещенное изображение на расстояние $r_{1}$ и $r_{2}$ по осям $X$ и $Y$ относительно центра изображения, а вид $C\left(r_{1}, r_{2}\right)-$ мерой их различия.

На рис. $1, c, d$ приведено 2D-представление автокорреляционных функций, рассчитанных при анализе результатов исследований поверхности пленки SBN-50 и сигнала пьезоотклика (доменной структуры), соответственно. Извлекая из полученного автокорреляционного изображения график радиально усредненных значений искомого параметра, можно определить средний латеральный размер кристаллитов и доменов по площади

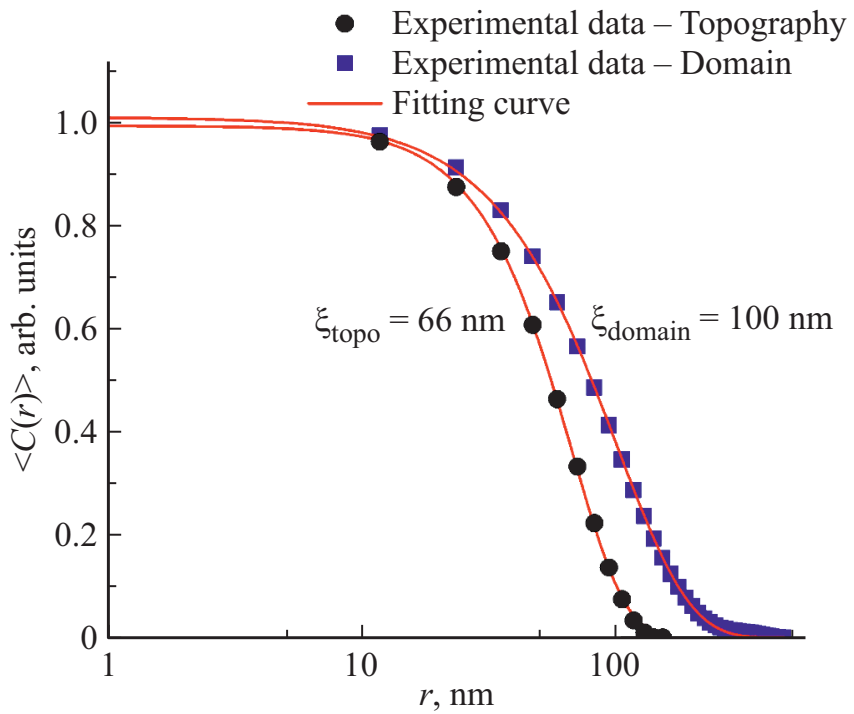

Рис. 2. Профили автокорреляционной функции (точки) и их аппроксимация уравнением (2) (линии) для гетероструктуры SBN-50/SRO $(001) / \mathrm{MgO}(001)$.

сканируемой поверхности пленки $\mathrm{SBN}-50$, используя уравнение вида [10]:

$$
\langle C(r)\rangle=A \cdot \exp \left[-(r /\langle\xi\rangle)^{2 h}\right],
$$

где $A-$ константа, $r-$ расстояние от центрального пика $(\mathrm{nm})$, определенное из изображения автокорреляционной функции, $\xi-$ среднее значение размера зерна $(\mathrm{nm}), h(0<h<1)$ - параметр. Расчеты показали (рис. 2), что средний латеральный размер кристаллитов составил $\sim 66 \mathrm{~nm}$, а сегнетоэлектрических доменов $\sim 100 \mathrm{~nm}$. Исследуемые пленки ниобата бария-стронция, как показано в [8,11], растут по механизму Фольмера-Веберра (стадия трехмерного зародышеобразования $\rightarrow$ разрастанием в сплошную пленку), т.е. рельеф поверхности является не результатом столбчатой или поликристаллической структуры пленки, а следствием механизма их роста [2], что и объясняет более крупную величину доменов.

На рис. 3 приведены температурно-частотные зависимости $\varepsilon / \varepsilon_{0} \quad$ и $\operatorname{tg} \delta$ гетероструктуры $\mathrm{Al} / \mathrm{SBN}-50 /$ $\mathrm{SrRuO}_{3}(001) / \mathrm{MgO}(001)$. При комнатной температуре в образце в анализируемом диапазоне частот имеет место дисперсия величины $\varepsilon / \varepsilon_{0}$ (снижается с 3050 до 1600) и $\operatorname{tg} \delta$ (снижаются с 0.1 до 0.3 ). По мере роста температуры в исследуемом образце, как и в случае керамики и монокристаллов SBN-50, наблюдается характерное для сегнетоэлектрика-релаксора (СЭР) изменение $\varepsilon / \varepsilon_{0}$ $(T, f)$ (при увеличении $T$ на зависимостях формируются максимумы при $T=T_{\max }$, сдвигающиеся в область высоких $T$ по мере роста $f$ ), проявляющееся непосредственно в области размытого сегнето-параэлектрического фазового перехода. Дисперсия $\varepsilon / \varepsilon_{0}$ практически полностью исчезает при $T>425 \mathrm{~K}$ и возрастает снова при 

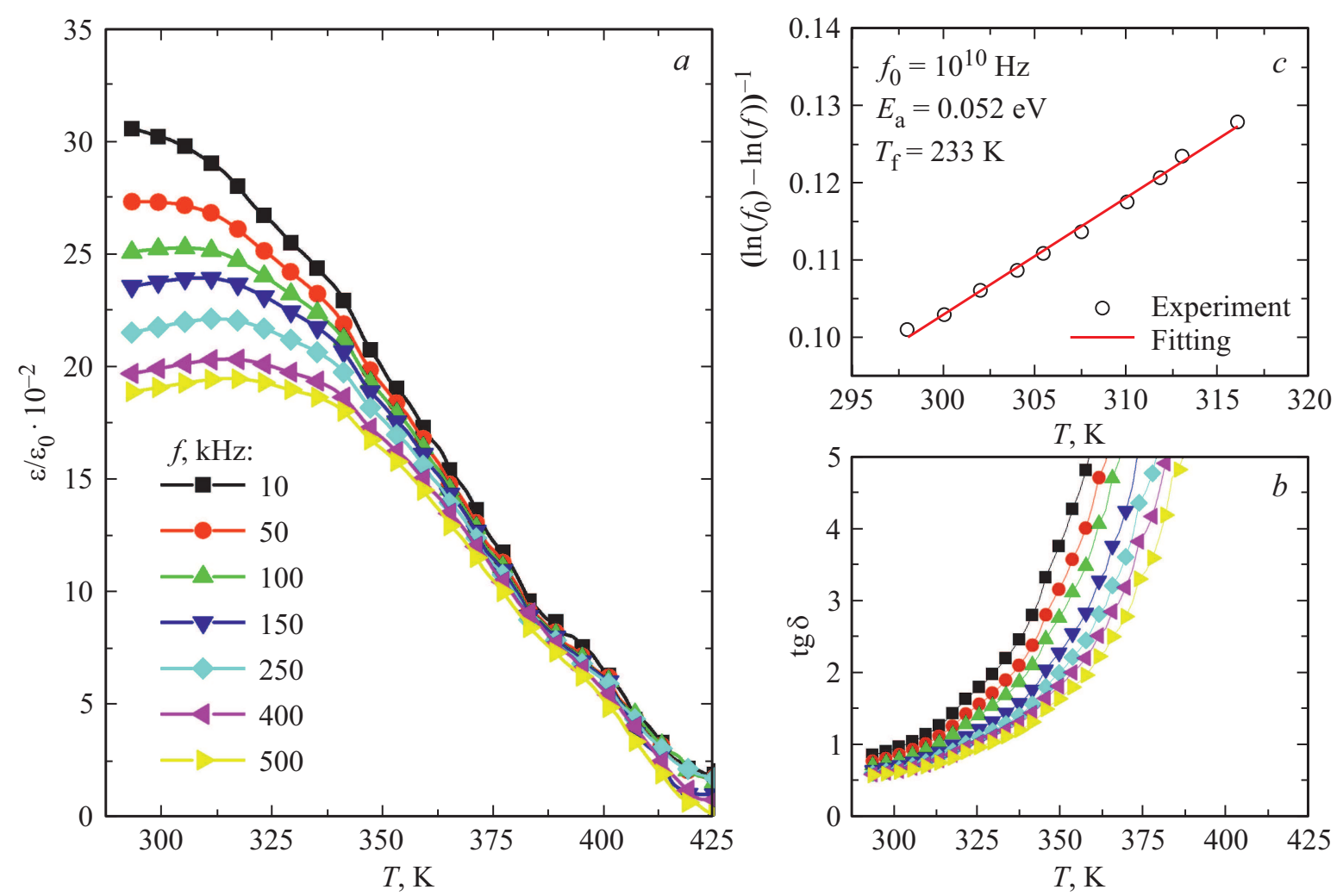

Рис. 3. Зависимости $\varepsilon^{\prime} / \varepsilon_{0}(T)(a)$ и $\operatorname{tg} \delta(T)(b)$ гетероструктуры $\mathrm{Al} / \mathrm{SBN}-50 / \mathrm{SRO}(001) / \mathrm{MgO}(001)$ при $T=280-425 \mathrm{~K} . c-$ зависимость $\left(\ln (f)-\ln \left(f_{0}\right)\right)^{-1}\left(T_{m}\right)$ (прямая линия - результат расчета по соотношению Фогеля-Фулчера).

$T>500 \mathrm{~K}$, что обусловлено, как видно из зависимостей $\operatorname{tg} \delta(T)$, ростом сквозной электропроводности в гетероструктуре, дающей вклад в мнимую часть комплексной диэлектрической проницаемости $\gamma_{s t} /\left(2 \pi f \varepsilon_{0}\right)$ (где $\gamma_{s t}-$ удельная электропроводность при $f \rightarrow 0 \mathrm{~Hz})$ и, как следствие, - в $\operatorname{tg} \delta=\varepsilon^{\prime \prime} / \varepsilon^{\prime}$. Зависимость $T_{m}(f)$ хорошо описывалась соотношением Фогеля-Фулчера (рис. 3,c):

$$
f=f_{0} \exp \left[E_{a c t} /\left(k \cdot\left(T_{m}-T_{f}\right)\right)\right]
$$

где $f_{0}$ - частота попыток преодоления потенциального барьера $E_{a c t}, k-$ постоянная Больцмана, $T_{f}-$ температура Фогеля-Фулчера, интерпретируемая как температура „статического замораживания“ электрических диполей.

Эти результаты свидетельствуют о том, что и в тонкопленочном состоянии SBN-50 так же является CЭР, при этом мы фиксируем сопоставимые с наблюдаемыми в монокристаллах и керамиках $\mathrm{SBN}-x$ значения $E_{a c t}$ и $f_{0}$, однако степень размытия фазового перехода в сравнении с ними расширилась. Релаксорные свойства в СЭР связывают с микроскопическим разупорядочением их структуры, что и приводит к фиксированию в них отличных от классических сегнетоэлектриков физических свойств. Каркас структуры твердых растворов SBN-x составляют два типа $\mathrm{NbO}_{6}$-октаэдров, объединенных кислородными вершинами: образованные узкие каналы треугольного сечения пусты; средние по диаметру каналы четырехугольного сечения $A 1$ заполняются только атомами $\mathrm{Sr}$, а наиболее крупные каналы пятиугольного сечения $\mathrm{A2}-\mathrm{Ba}$ и $\mathrm{Sr}$. Величина вероятности заполнения катионами $\mathrm{Ba}$ и $\mathrm{Sr}$ структурных позиций, по мнению различных авторов, разнится, однако можно утверждать [3], что заселенность канала $A 1$ атомами $\mathrm{Sr}$ слабо зависит от состава, а релаксорные характеристики $\mathrm{SBN}-x$ в основном определяются статистикой заселения каналов $A 2$ атомами Ba и Sr. Эта неупорядоченность в расположении катионов сохраняется и в ТП, при этом наличие в пленке деформационных полей, возникающих, в частности из-за различия коэффициентов температурного расширения (КТР) материалов подложки и пленки, как усиливают степень размытия фазового перехода, так и смещают его по температуре. Это проявилось при анализе сегнетоэлектрических свойств гетероструктуры. В отличии от монокристаллов, зависимости $P(U)$ для пленки SBN-50, измеренные вдоль полярной оси, были достаточно узкие, что говорит о малых величинах остаточной поляризации и коэрцитивных полей. При приложении более высоких электрических полей фиксировался вклад в отклик токов утечки, приводящих к пробою пленки. Исследования СЭ-усталости выявили (рис. $4, b$ ), что процесс переключения поляризации в пленке и ее поляризационные характеристики сохраняются вплоть до $10^{10}$ циклов переключения. Ассиметричный вид пет- 

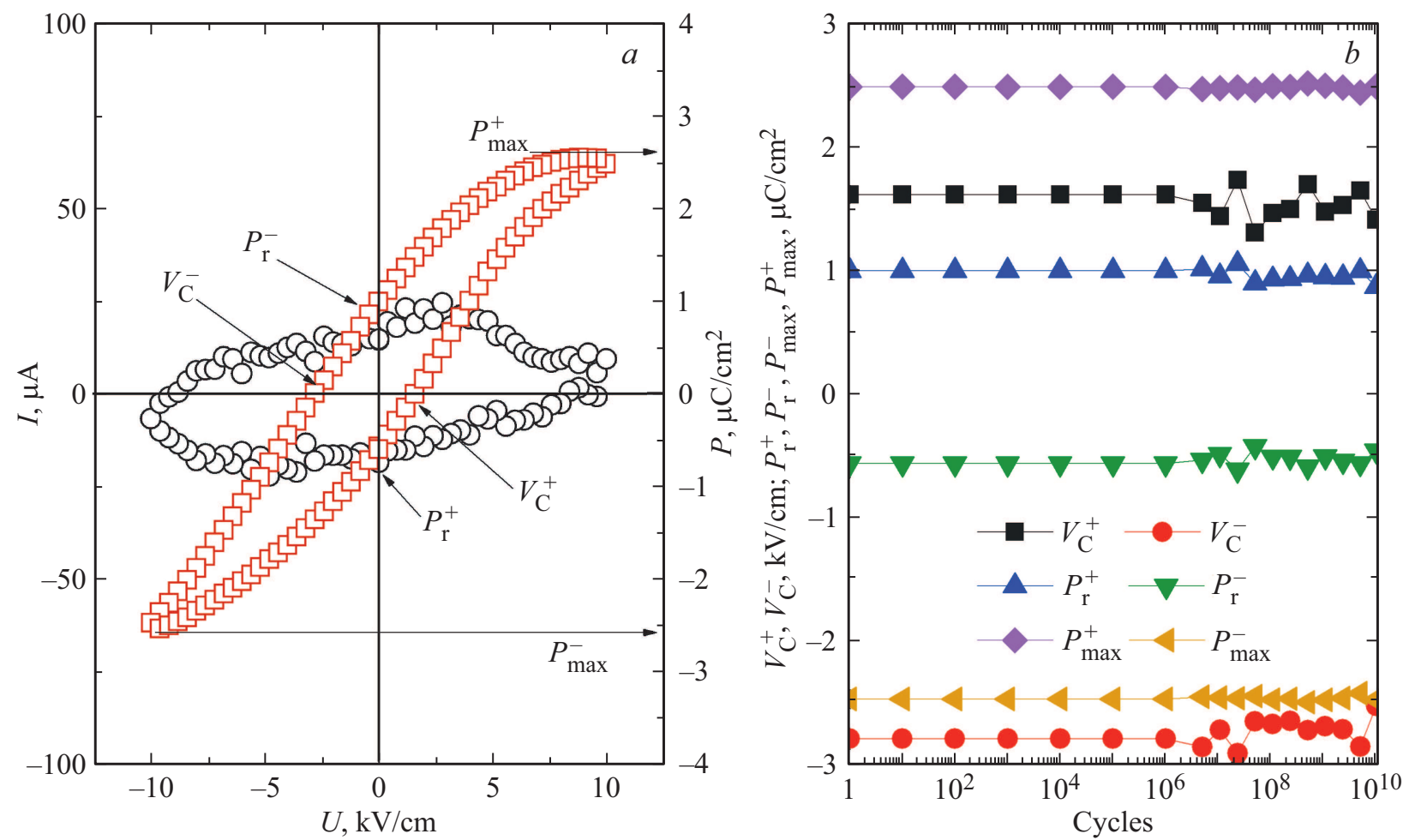

Рис. 4. $a$ - зависимость $P(U)$ гетероструктуры $\mathrm{Al} / \mathrm{SBN}-50 / \mathrm{SRO}(001) / \mathrm{MgO}(001)$ при комнатной температуре на частоте $1000 \mathrm{~Hz}$, $b$ - зависимости поляризационных характеристик материала от количества циклов переключения.
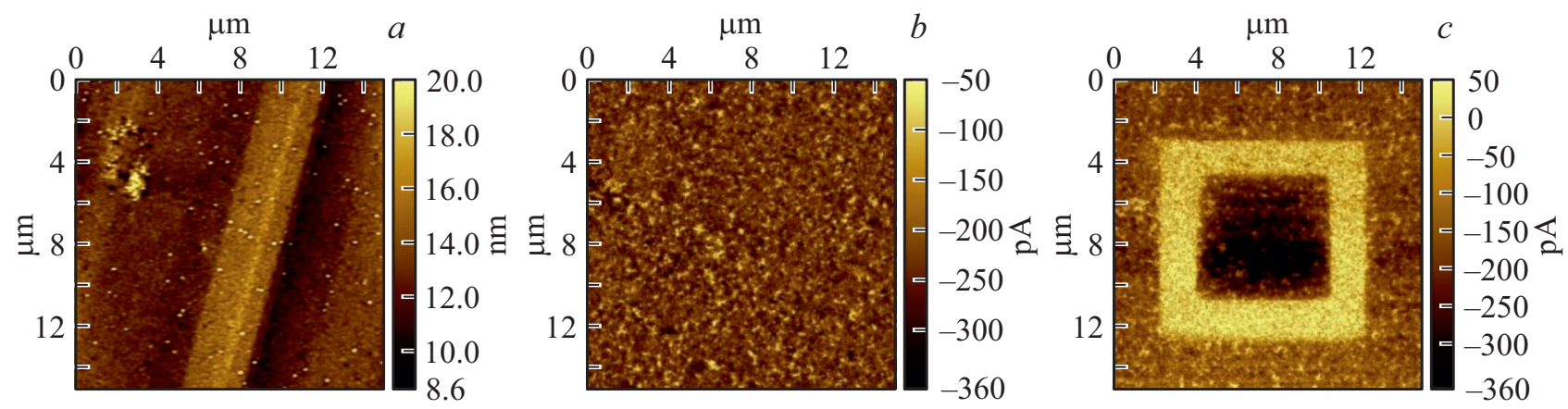

Рис. 5. Топография поверхности $(a)$, исходный сигнал пьезоотклика $(b)$, после поляризации $(c)$ (светлый квадрат: $+10 \mathrm{~V}$, темный: $-10 \mathrm{~V})$.

ли, сохраняющийся при цикловании, свидетельствует о наличии внутреннего поля, что проявилось так же и при исследовании пьезоэлектрических характеристик пленки методами СМП и КМ (рис. 5). Исходный сигнал пьезоэлектрического отклика (рис. 5,b) имеет отрицательные значения (см. вертикальную $Z$-шкалу), т.е. пленкам свойственна самопроизвольная поляризация, направленная от подложки к поверхности пленки, связанная с наличием в ней внутреннего поля. Это также является и причиной фиксирования асимметрии зависимостей $P(U)$ (рис. 4,a). Самопроизвольная поляризация в тонких СЭ-пленках наблюдается часто в отличие от крупнокристаллических образцов, и связывается главным образом с двумя механизмами [12]: возникновением на границе раздела пленка-электрод объемного заряда, поле которого и поляризует пленку, или же результатом воздействия на сегнетоэлектрик при эпитаксиальном росте двумерных механических напряжений со стороны подложки. С нашей точки зрения, в подавляющем большинстве случаев имеют место оба механизма, но вклад их может быть различен. Учитывая, что мы не фиксировали усталости зависимостей $P(U)$, а также характеристики пленки SBN-50 после отжигов восстанавливались, в нашем случае главную роль играет второй механизм.

В процессе поляризации (рис. 5,c) пленки удалось сформировать устойчивые области с различной ориентацией поляризации (от подложки и к подложке), 

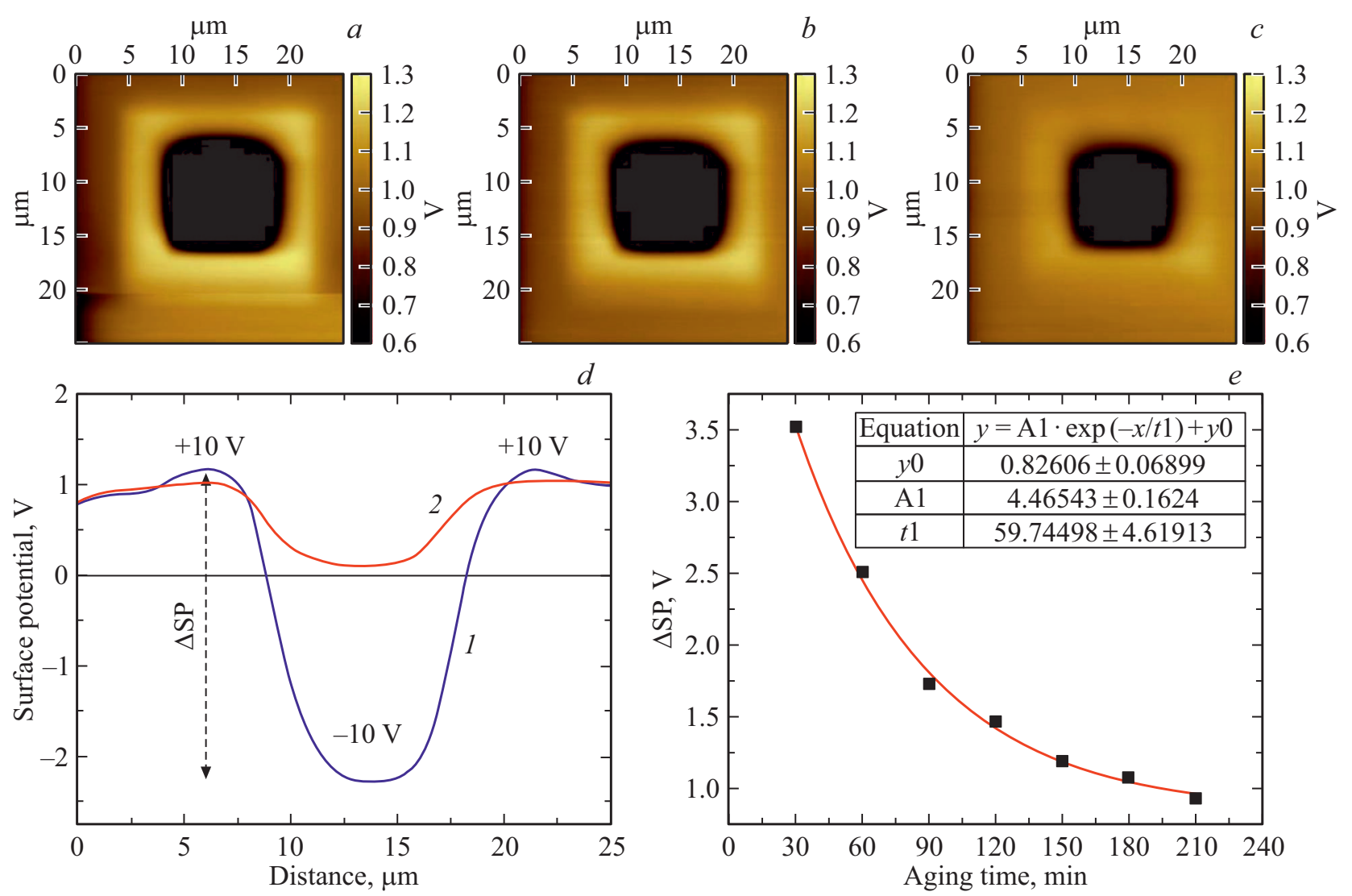

Рис. 6. Поверхностный потенциал поляризованной пленки SBN-50, полученные через 30 (a), 60 (b) и 150 min (c) после предварительной поляризации в режиме СМП. $d$ - профили сигнала поверхностного потенциала через 30 (кривая 1 ) и 210 тіn (кривая 2) после поляризации вдоль линий на сканах, $e-$ временная зависимость сигнала $\Delta \mathrm{SP}$.

что так же подтверждает сегнетоэлектрические свойства структуры. В режиме КМ проведены исследования релаксации заполяризованных областей, которые были предварительно получены в режиме СМП напряжением $\pm 10 \mathrm{~V}$. На рис. $6, a$ светлый квадрат отражает результат приложения $+10 \mathrm{~V}$ на кантилевер сканирующего зондового микроскопа, и центральный темный квадрат поляризацию при $-10 \mathrm{~V}$. Режим КМ был выбран ввиду того, что является бесконтактным, т.е. зонд не контактирует с поверхностью образца как в случае СМП, где регистрация сигнала пьезоотклика происходит в непосредственном контакте зонда с поверхностью пленки при приложении переменного напряжения амплитудой $5 \mathrm{~V}$. Если считать, что проводящий зонд играет роль верхнего электрода, то в рассматриваемом случае получим значение напряженности поля под кантилевером более $20 \mathrm{kV} / \mathrm{cm}$. Это значение превышает коэрцитивное поле для гетероструктур на основе $\mathrm{SBN} \sim 2-3 \mathrm{kV} / \mathrm{cm}$, что способствует процессу деполяризации индуцированной области непосредственно в процессе сканирования, что и учитывалось при дальнейших исследованиях.

Анализ показал, что контраст индуцированных областей, визуализированный именно в КМ, сохраняется в течение нескольких часов. На рис. 6, $d$ представлены профили сигнала поверхностного потенциала через
$30 \mathrm{~min}$ после поляризации (кривая 1) и $210 \mathrm{~min}$ (кривая 2), проведенные посередине соответствующих сканов, полученные в режиме КМ. Обращает на себя внимание сильная асимметрия в величине сигнала поверхностного потенциала для областей, заполяризованных при $+10 \mathrm{~V}$ и $-10 \mathrm{~V}$. Из представленного на рис. 6, e графика, иллюстрирующего релаксацию поляризованного состояния в гетероструктуре $\mathrm{SBN}-50 / \mathrm{SRO} / \mathrm{MgO}(001)$, видно, что в сравнении с классическими сегнетоэлектриками релаксация поляризованного состояния (в нашем случае это величина $\Delta \mathrm{SP}$ - уровень сигнала поверхностного потенциала между „+““ и „-“ областями, рис. 6,d) протекает довольно быстро по экспоненциальному закону. Это связано, с одной стороны, с низкими величинами коэрцитивных полей, вследствие чего поляризованное состояние разрушается из-за термоактивационного механизма, а с другой - существованием внутреннего поля в пленке (как видно из рис. 4, $a$ его величина более $1 \mathrm{kV} / \mathrm{cm})$. Именно наличие последнего, сформированного на стадии роста пленки SBN-50, и приводит к тому, что отрицательно заполяризованная область (т.е. против направления самопроизвольной наполяризованности) реллаксирует быстрее, чем положительная. В дальнейшем она сохраняется в течение довольно 
длительного времени и полностью исчезает только при термической деполяризации образца.

\section{4. Выводы}

1. Пленки ниобата бария-стронция SBN-50, выращенные на подложке $\mathrm{SRO} / \mathrm{MgO}(001)$ методом ВЧ-катодного напыления, по данным сканирующей зондовой микроскопии характеризуются высокой однородность и низкой шероховатостью поверхности, при этом латеральные размеры кристаллитов и доменов, рассчитанные с использованием метода автокорреляционной функции составили 66 и $110 \mathrm{~nm}$ соответственно.

2. Диэлектрические измерения пленки SBN-50 в обычной конденсаторной топологии (нижний электрод $\mathrm{SRO}$, верхний - Al) показали, что по характеру зависимостей $\varepsilon / \varepsilon_{0}(T, f), \operatorname{tg} \delta(T, f)$ и $T_{m}(f)$ материал относится к СЭР. Область ФП размывается и, как следствие, при комнатной температуре характеризуется высокими значениями $\varepsilon / \varepsilon_{0}(1600-3000)$, низкими остаточной поляризации и коэрцитивных полей, усталость которых не наблюдается вплоть до $10^{10}$ циклов переключения.

3. Анализ временной эволюции профиля сигнала поверхностного потенциала в режиме КМ, созданного поляризацией областей пленки SBN-50, выявил сильную асимметрию в его величине и разницу в релаксации для областей с различным направлением поляризации, что связано с низкими значениями коэрцитивного поля пленки и одновременно наличием внутреннего поля.

\section{Финансирование работы}

Работа выполнена в рамках реализации государственного задания ЮНЦ РАН (тема госрегистрации № 01201354247) и гранта Президента РФ № МК-678.2020.2. Исследования методами СЗМ выполнены на оборудовании ЦКП „Материаловедение и металлургия“ НИТУ „МИСиС“ и при финансовой поддержке Министерства науки и высшего образования РФ в рамках государственного задания (проект № 0718-2020-0031).

\section{Конфликт интересов}

Авторы заявляют, что у них нет конфликта интересов.

\section{Список литературы}

[1] S. Trolier-McKinstry, P. Muralt. J. Electroceramics 12, 7 (2004).

[2] В.М. Мухортов, Ю.И. Юзюк. Гетероструктуры на основе наноразмерных сегнетоэлектрических пленок: получение, свойства и применение. ЮНЦ РАН, Ростов н/Д. (2008). $224 \mathrm{c}$.

[3] Ю.С. Кузьминов. Сегнетоэлектрические кристаллы для управления лазерным излучением. Наука, М. (1982). $400 \mathrm{c}$.
[4] С.А. Борисов, Н.М. Окунева, С.Б. Вахрушев, А.А. Набережнов, Т.Р. Волк, А.В. Филимонов. ФТТ 55, 2, 295 (2013).

[5] S. Gupta, A. Paliwal, V. Gupta, M. Tomar. Opt. Laser Technology 137, 106816, 1 (2021).

[6] В.М. Мухортов, Ю.И. Головко, А.В. Павленко, Д.В. Стрюков, С.В. Бирюков, А.П. Ковтун, С.П. Зинченко. ФТТ 60, 9, 1741 (2018).

[7] P.R. Willmott, R. Herger, B.D. Patterson, R. Windiks. Phys. Rev. B 71, 144114 (2005).

[8] А.В. Павленко, И.Н. Захарченко, Ю.А. Кудрявцев, Л.И. Киселева, С.Х. Алихаджиев. Неорган. материалы 56, 11, 1252 (2020).

[9] I. Horcas, R. Fernández, J.M. Gomez-Rodriguez, J.W.S.X. Colchero, J.W.S.X.M. Gómez-Herrero, A.M. Baro. Rev. Sci. Instruments 78, 1, 013705 (2007).

[10] R.C. Munoz, G. Vidal, M. Mulsow, J.G. Lisoni, C. Arenas, A. Concha, R. Esparza. Phys. Rev. B 62, 7, 4686 (2000).

[11] А.В. Павленко, Д.В. Стрюков, Л.И. Ивлева, А.П. Ковтун, К.М. Жидель, П.А. Лыков. ФТТ 63, 2, 250 (2021).

[12] А.Г. Канарейкин, Е.Ю. Каптелов, С.В. Сенкевич, И.П. Пронин, А.Ю. Сергиенко, О.Н. Сергеева. ФТТ 58, 11, 2242 (2016).

Редактор Т.Н. Василевская 